\title{
ANÁLISE DAS BOMBAS TRANSPORTADORAS DE MISCELA EM UMA FÁBRICA DE ÓLEO DE SOJA
}

\author{
Eduardo R. A. Prado ${ }^{1}$ \\ Gabriela F. Lopes ${ }^{2}$
}

Resumo: O seguinte artigo relata um projeto realizado em uma fábrica de óleo de soja na etapa de extração do óleo, que conta, em sua destilaria e processos de absorção e dessorção, com bombas para deslocar a miscela ou óleo mineral, dependendo do local, de um equipamento a outro. Pelo fato de que o número de bombas existentes era igual ao número de bombas necessárias nesses processos, não se trabalhava com bombas de reserva. Por isso, quando havia necessidade de manutenção nessas bombas, a planta industrial inteira era parada e, assim, perdia-se em quantidade de produção e, consequentemente, em retorno financeiro. $\mathrm{O}$ projeto analisou quais bombas deveriam ser compradas e qual a possibilidade de utilizar bombas disponíveis na fábrica como reservas das bombas existentes, agrupando-as, e encontrando uma solução economicamente viável para a eliminação, ou no mínimo redução, das paradas na planta industrial devido à manutenção das bombas.

Palavras-chave: Bomba, destilação de miscela, manutenção, parada industrial.

Abstract: The following article describes a project carried out in an oil mill soybean oil extraction stage that account in his distillery and processes of absorption and desorption, with pumps to move the micelle or mineral oil, depending on the location, a machine to another. Because the number of existing pumps was equal to the number of pumps needed in this process, it pumps working with reservation. Therefore, when there need to maintain these pumps, the entire industrial plant was stopped and thus lost in production quantities and thus financial return. The project analyzed which pumps should be bought and which the possibility of using pumps available in the factory as reserves of existing pumps, grouping them, and finding an economically viable solution to eliminate or at least reduce, the charts in industrial plant due to maintenance of the pumps.

Keywords: Pump, distillation of micelle, maintenance, industrial shutdown.

\footnotetext{
${ }^{1}$ Departamento de Engenharia Química, Universidade Estadual de Maringá. E-mail: dudarasi@yahoo.com.br

2 Departamento de Engenharia Química, Universidade Estadual de Maringá. E-mail:

gabilopes.92@hotmail.com
} 


\section{INTRODUÇÃO}

A cultura agrícola que mais cresceu nas últimas três décadas, segundo dados do Ministério da Agricultura, foi a soja, correspondendo a quase metade da área plantada em grãos do Brasil. Essa produção visa, em grande parte, abastecer as indústrias de óleo de soja do país, cujo processo inclui, após o armazenamento dos grãos de soja, as etapas de ressecagem, preparação, extração e refino, até chegar às prateleiras dos mercados para consumo.

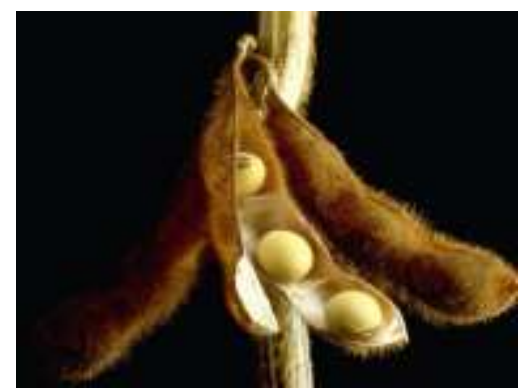

Figura 1. Soja: Vagem e grãos

Quando a soja chega à fábrica transportada por caminhões, ela é primeiramente classificada, analisando-se caraterísticas como sua umidade, coloração e granulometria. Em seguida, o caminhão passa por um tombador, para pesar a carga e a soja vai para um processo de pré-limpeza, retirando-se as maiores impurezas presentes. Depois disso, vai para a primeira etapa de secagem para que não fique armazenada com grande umidade, já que isso pode danificar a qualidade da soja e, então, tendo passado por esses processos, a mesma pode ir para os armazéns, onde fica até entrar no processo de obtenção do óleo de soja.

A primeira etapa do processo em si, a ressecagem, consiste na pré-limpeza dos grãos que estavam armazenados, seguida da sua entrada em um secador, com os objetivos de retirar impurezas novamente e cascas e diminuir ainda mais a sua umidade para o segundo armazenamento. A soja entra no secador com aproximadamente $13 \%$ de umidade e sai dele com aproximadamente $10 \%$, sendo transportada até silos de armazenamento. Já na segunda etapa, a preparação, há diversas subetapas, sendo que a soja, ao sair do silo passa por uma balança, quebradores, colunas de ar, peneiras, um condicionador, laminadores e uma expander. A passagem pela balança é para que seja feita a pesagem da soja ao entrar na preparação e, dessa forma, se tenha um controle dessa quantidade de forma intermitente. $\mathrm{Na}$ quebra da soja, a soja se parte em pedaços menores, diminuindo a distância da sua superfície às bolsas de óleo, sendo chamada a partir desse ponto de polpa. Em seguida, através de colunas de ar e das peneiras é feita uma nova retirada de cascas e impurezas leves, para que as mesmas não ocupem o espaço da soja no extrator e acabem diminuindo o rendimento do mesmo. Essas cascas retiradas vão para ciclones e, então, juntamente com o pó retirado durante a quebra da soja, passam por uma peletização e são levadas para armazenagem. Há, então, a passagem da polpa por um condicionador para aumentar sua umidade e de certa forma "cozinhá-la", para facilitar a etapa seguinte do processo, a laminação. $\mathrm{O}$ conjunto de laminadores tem como objetivo aumentar a área superficial da soja, transformando-a numa massa que se divide, indo uma parte direto para o extrator e outra parte para um ou mais expansores, para iniciar a retirada do óleo por prensagem, resultando numa massa que entrará, juntamente com a massa apenas laminada, na última etapa antes de se obter óleo bruto: a extração.

Essa etapa determinante na eficiência de uma planta industrial de soja, a extração, é realizada na grande maioria dos casos com a atuação de um solvente. Ela se dá a partir da transferência de massa que ocorre no contato entre o solvente e a massa de soja, em que o óleo se desprende da fase sólida e é transferido para a fase líquida formando a chamada miscela, ou seja, o óleo misturado ao solvente.

Entre as possibilidades existentes para se realizar a extração do óleo estão o método do extrator em batelada, e os métodos de sistemas contínuos tanto por imersão, baseado na extração através da 
difusão, quanto por percolação, em que se predomina a extração por solução e que é a opção mais escolhida, já que exige uma menor preocupação com a posterior filtração para retirar sólidos finos de soja em suspensão na miscela (Paraíso, 2001).

Um dos extratores por percolação mais utilizados tem a forma de um cilindro dividido em setores, nos quais é colocada a massa de soja mantida a baixa rotação, o chamado Rotocel. A massa inicial é percolada com a miscela mais concentrada e em seguida, gradativamente, com miscelas mais diluídas, até, por fim, a entrada do solvente puro (Embrapa, 2001).

Obtêm-se, assim, dois produtos dessa extração: a miscela, produto principal, e a torta, ou seja, o farelo ainda úmido de solvente, que se deixa cair na parte inferior no setor do extrator em que se faz entrar o solvente puro.

O solvente utilizado nesse tipo de extração é um solvente químico orgânico que, praticamente na totalidade dos casos, é o hexano. De acordo com Corrêa (2010), os principais parâmetros para serem analisados ao se escolher um solvente são a seletividade, ou seja, a facilidade do solvente de extrair um componente da solução em relação aos demais, a sua recuperabilidade no processo; densidade; tensão interfacial, em que altos valores indicam dificuldade de adequada dispersão e baixos valores podem causar emulsões estáveis no extrator; reatividade química, que pode acarretar formação de produtos indesejados; corrosividade, para evitar danos aos equipamentos; pressão de vapor, para viabilizar a operação à pressão atmosférica; e custos, para tornar viável economicamente o processo. Dessa forma, o hexano se encaixa como um solvente adequado para a extração do óleo de soja, já que satisfaz a maioria das exigências anteriores: é imiscível em água; dissolve com facilidade o óleo, não agindo sobre outros componentes dos grãos; possui composição homogênea e estreita faixa de temperatura de ebulição; e tem baixo calor latente de ebulição. $O$ hexano apresenta, porém, algumas desvantagens como a alta inflamabilidade e o alto custo (Embrapa, 2001). Devido a essas características é indispensável a sua recuperação após a extração, tanto da miscela, como da torta.

A recuperação do solvente presente na miscela é realizada através de destilação. Esta, segundo Roitman (2002), é uma operação que permite a separação de misturas de líquidos por meio de evaporação dos componentes em questão, ou seja, a separação em uma coluna de destilação acontece devido à volatilidade relativa de um componente com relação ao outro, cujo agente de separação é o calor.

Já a torta que sai do extrator deve passar por um equipamento que retire o hexano da mesma. Atualmente, o equipamento mais usado é o dessolventizador-tostador, um aparelho que consiste de sete estágios e combina a evaporação do solvente, nos dois primeiros estágios, com a umidificação e tostagem do farelo nos estágios seguintes, sendo que para reduzir esse teor de umidade ao limite desejado, o material é novamente seco após a saída do tostador (Embrapa, 2001).

Já os gases que saem do dessolventizador-tostador trocam calor com a miscela, em que o hexano também está presente, até que todo o hexano vá para os gases, que então passam por processos de absorção por óleo mineral, condensação e posterior decantação da água e do hexano para o retorno do solvente ao extrator. A decantação é possível porque, segundo a FISPQ do hexano (2011), a solubilidade do hexano na água é desprezível e sua densidade é de $0,67 \mathrm{~g} / \mathrm{cm}^{3}$, sendo menos denso que a água. Já a absorção, segundo Roitman (2002), é uma operação em que uma mistura gasosa é colocada em contato com um líquido para nele serem dissolvidos um ou mais compostos que se quer remover da mistura gasosa, nesse caso o hexano. No processo ela é seguida pela dessorção que, segundo Cunha et al. (2006), refere-se ao fenômeno de retirada de substâncias adsorvidas ou absorvidas por outras. Com ela, torna-se o óleo mineral possível de ser reutilizado no 
processo, após aquecê-lo e ter introduzido no mesmo vapor direto.

Para deslocar a miscela ou o óleo mineral de um equipamento até outro, a etapa de extração de uma indústria necessita de bombas. Sendo máquinas geratrizes, elas transformam o trabalho mecânico que recebem de um motor em energia hidráulica sob as formas que o líquido é capaz de absorver, isto é, energia potencial, de pressão e cinética, podendo ser classificadas em bombas de deslocamento positivo ou volumétricas, turbobombas ou hidrodinâmicas e bombas especiais, de acordo com o modo pelo qual é realizada a transformação do trabalho mecânico em energia hidráulica, assim como o modo de cedê-la ao líquido (Moraes, 1998).

As bombas de deslocamento positivo ou volumétricas, segundo Silva (2003), tem por característica de funcionamento a transferência direta da energia mecânica cedida pela fonte motora em energia potencial, sendo que há a movimentação de um órgão mecânico da bomba que obriga o fluido a executar o mesmo movimento do qual ele está animado. O nome dessas bombas vem do fato de que o líquido enche e é expulso dos espaços com volume determinado no interior das mesmas. As turbobombas, por outro lado, segundo Moraes (1988), são bombas que possuem um órgão rotatório dotado de pás chamado rotor, que comunica aceleração à massa líquida, transformando a energia mecânica de que está dotado em energia cinética. Essa aceleração, diferentemente das bombas de deslocamento positivo, não possui a mesma direção e o mesmo sentido do movimento do líquido em contato com as pás.

Pelo tipo de trabalho que realizam, essas máquinas exigem periodicamente uma manutenção, que segundo Bornia (1995), é um exemplo de atividade auxiliar, que não agrega valor aos produtos, porém é necessária para dar suporte ao trabalho efetivo, sendo indispensável.

\section{OBJETIVOS}

Redução nas paradas da planta industrial de óleo de soja devido à manutenção de bombas da destilaria e da absorção da etapa de concentração do óleo de soja, utilizando-se bombasreserva.

\section{CONTEXTUALIZAÇÃO}

A destilaria da extração de uma indústria de óleo de soja inclui colunas recuperadoras de gases, economizadoras, aquecedores, condensadores, colunas de destilação, e há também colunas de absorção e dessorção do hexano feitas com óleo mineral. Assim que é feita a extração, a miscela, com uma concentração de até $28 \%$ em massa de óleo, vai para um tanque de armazenamento e é succionada por uma primeira bomba que dá força à miscela para chegar até a primeira coluna de destilação economizadora, ou seja, que não utiliza vapor para o aquecimento, mas o calor dos gases que saem do dessolventizador. Em seguida, essa miscela, já com uma concentração de até $42 \%$ de óleo, é succionada por uma segunda bomba e chega até uma segunda economizadora, tornando a miscela ainda mais concentrada em óleo. Depois de ser succionada por uma terceira bomba, ela, agora concentrada em até $77 \%$, passa por um trocador de calor, cuja fonte de calor é o próprio óleo bruto antes de ser refinado, em seguida por um aquecedor, cuja fonte de calor é vapor encamisado e ainda uma coluna de evaporação na qual é feito o contato da miscela com vapor direto, e a mesma sai da coluna já com uma concentração de até $99 \%$ de óleo. Por fim, a miscela é succionada por outra bomba para ser enviada a uma última e importante coluna de destilação que funciona com injeção de vapor d'água superaquecido em estágios, a coluna de stripping. Ela funciona a baixas pressões e depois que o vapor superaquecido entra em contato em contracorrente com a miscela, os últimos resíduos de hexano são retirados e, então, dela já sai o óleo bruto que é enviado à refinaria da fábrica. Um fluxograma sintetizado do processo pode ser visto em seguida na figura 2 . 


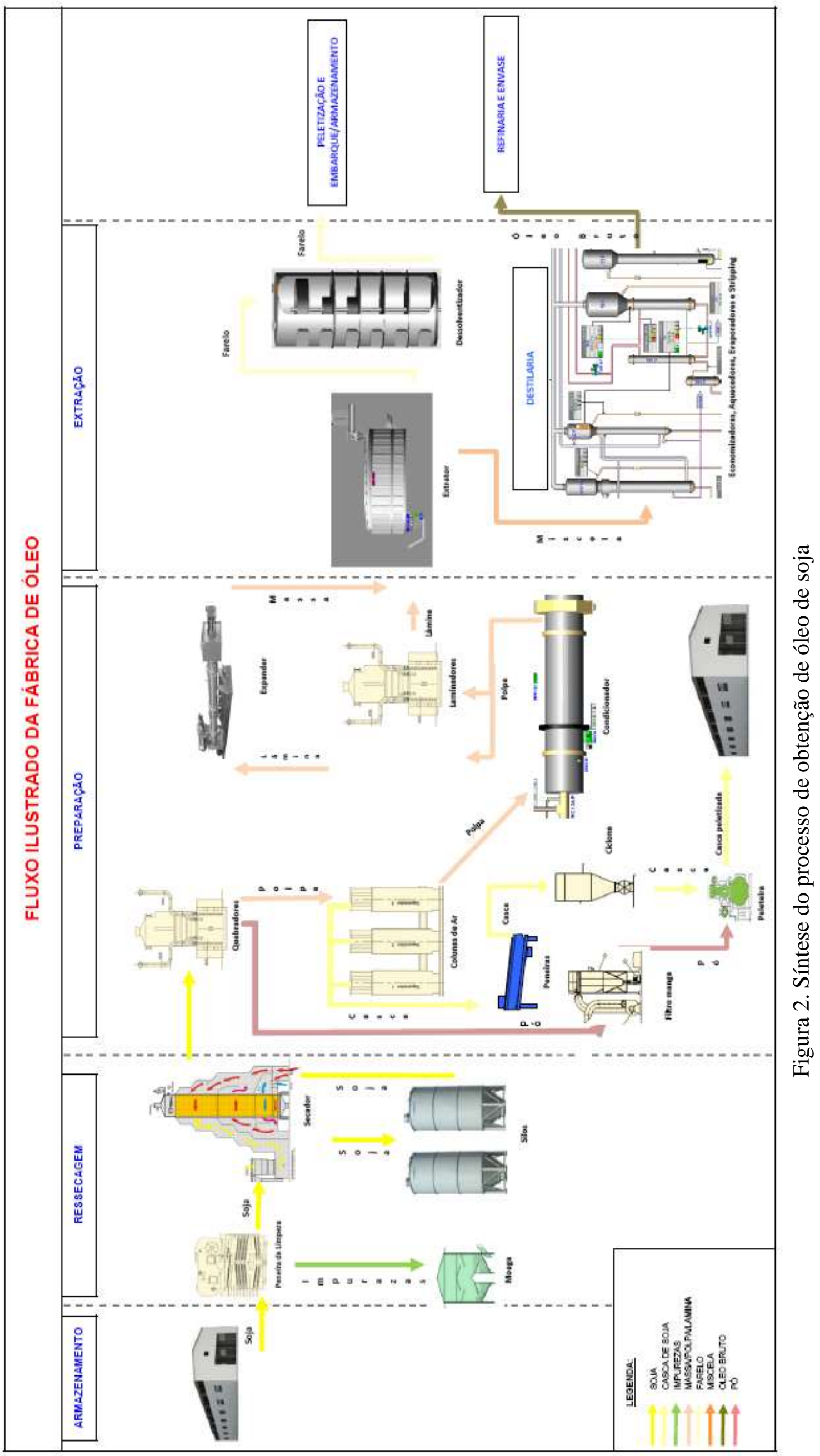


Entretanto, no que diz respeito ao óleo mineral, os gases que passam pelas colunas economizadoras entram em dois condensadores em série, e o que não se condensou até então entra na coluna de absorção com óleo mineral, o qual se torna concentrado em $2 \%$ de hexano. Em seguida, esse óleo, após succionado por uma primeira bomba, é aquecido em um trocador de calor e também em um aquecedor e entra em uma coluna de dessorção com vapor direto, saindo da mesma com uma concentração de hexano menor que $0,1 \%$. A bomba que o succiona, o envia para dois trocadores de calor o resfriar e novamente para a coluna de absorção para ser reutilizado.

Com uma destilaria com o número de bombas instaladas idêntico ao número de bombas necessárias para fazer todo o trabalho de sucção e recalque nas colunas de destilação, de absorção e de dessorção, não se trabalhava com qualquer bomba como reserva. Dessa forma, quando por algum motivo, precisava-se fazer manutenção em alguma delas, era necessário que todo o processo industrial fosse parado para que o problema fosse resolvido, perdendo-se em produção e, dessa forma, em lucro.

Vários motivos exigem a manutenção corretiva das bombas, como necessidade de troca de juntas, rolamentos, chavetas ou pneus do acoplamento, entre outros. E por esses motivos, cinco meses antes da realização desse trabalho as paradas da fábrica somaram quase 12 horas, o que significou uma perda da produção de 1.234 toneladas de massa de soja, ou seja, aproximadamente 950 toneladas de farelo e 234 toneladas de óleo degomado. Essa produção corresponderia a um total de quase mais de 33 mil reais de lucro líquido nesses cinco meses e, se o layout da fábrica continuasse o mesmo, isso levaria a mais de 66 mil reais que deixaria de se ganhar nesse ano, já que a fábrica tem uma parada anual programada de quase 2 meses.

Alinhado a essa problemática, havia também o fato de que, devido a um investimento de anos atrás num novo extrator, as bombas do extrator antigo ficaram sobrando na fábrica sem ser utilizadas, o que representava uma possível solução para as paradas da fábrica, utilizando-as como bombasreserva e evitando grandes gastos. A confirmação dessa possibilidade ou da necessidade da compra de bombas novas, todavia, dependia dos resultados de análises das condições das bombas que estavam sendo utilizadas até então na destilaria e nos processos com óleo mineral, das tubulações ligadas às mesmas, além das bombas disponíveis no antigo extrator.

\section{PROCEDIMENTO}

Como a manutenção de cada bomba, apesar de representar prejuízos à fábrica, não era tão frequente durante o ano e geralmente não ocorria ao mesmo tempo em mais de uma das bombas, definiu-se que a melhor solução seria não colocar uma bomba-reserva para cada bomba do processo, mas uma bombareserva para cada duas bombas.

Sabendo que todas as bombas até então instaladas nessa parte da fábrica eram bombas do tipo turbobombas, centrífugas mais especificamente, não houve dificuldades para definir que esse seria o tipo definido para as bombasreserva, já que, pela própria experiência com as turbobombas, sabia-se que elas eram adequadas para os fluidos que utilizaríamos. As bombas centrífugas puras ou radiais, de acordo com Silva (2003), são aquelas nas quais a direção do fluido bombeado é perpendicular ao eixo de rotação.

Já para a escolha do tamanho adequado de cada bomba necessária, seguiram-se os conceitos de Moraes (1988). Segundo ele, para tal escolha é necessário entrar com os valores da altura manométrica $(\mathrm{H})$ ou pressão $(\mathrm{p})$ e da vazão (Q) nos catálogos de seleção fornecidos por fabricantes.

Deve-se aplicar o balanço energético entre dois pontos adequados para se calcular a altura manométrica, ou seja, a energia por unidade de peso que a bomba deve fornecer para deslocar um fluido a uma dada velocidade de um 
reservatório até outro, através de tubulações de diâmetros definidos, vencendo o desnível geométrico e a resistência. Dessa forma, entre dois pontos, a fórmula que deve ser utilizada para encontrá-la é:

$$
H=\frac{\left(P_{2}-P_{3}\right)}{\gamma}+\left(Z_{2-1}\right)+\frac{\left(V_{2}^{2}-v_{1}^{2}\right)}{2 y}+l_{w}
$$

Sendo que, $P_{2}$ é a pressão no ponto $2, P_{1}$ é a pressão no ponto $1, \gamma$ é o peso específico do fluido, $Z_{2-1}$ é a diferença de altura entre os dois pontos, $V_{2}$ é a velocidade no ponto $2, V_{1}$ é a velocidade no ponto $1, \mathrm{~g}$ é a aceleração da gravidade e $l_{w}$ é a perda de carga total.

A perda de carga, ou seja, a perda de energia do fluido durante seu deslocamento, resulta, segundo Moraes, da sua viscosidade, da resistência oferecida pelas paredes da tubulação em virtude de sua rugosidade, e das alterações nas trajetórias das partículas líquidas impostas pelas peças e dispositivos intercalados nos encanamentos. Dessa forma, para encontrar seu valor deve-se somar a perda de carga ao longo do encanamento, ou seja, a perda de carga considerando que a tubulação fosse toda reta e de seção circular constante, à perda de carga devido a acidentes da tubulação.

Deveria definir-se também, quais pontos de operação entre as bombas em utilização eram mais parecidos para que pudesse definir quais delas seriam agrupadas com uma mesma bomba reserva. Pelo fato das bombas do antigo extrator e das bombas utilizadas no momento na destilaria e na absorção e dessorção com óleo mineral serem bombas muito antigas, não havia registros adequados dos pontos de operação de cada uma e garantia do seu correto dimensionamento. Por isso, foi necessário, primeiramente, encontrar os valores de vazão e altura manométrica de cada bomba em operação, para que se pudesse compará-las entre si e com as bombas disponíveis ou as necessárias de compra.

Tanto para a destilaria, como para o sistema de absorção e dessorção, havia o registro das concentrações de óleo da miscela de cada bomba e do valor real da vazão mássica em uma delas, podendo-se encontrar as vazões das demais bombas do processo com um balanço de massa. Para que fosse feito o balanço de massa, foi necessário encontrar a densidade da miscela em cada bomba. Ela foi encontrada fazendo medidas no laboratório da fábrica, com o auxílio de um picnômetro, instrumento com tampa perfurada no qual o volume do fluido que contém é invariável. Assim, foi possível encontrar, primeiramente com o balanço, as vazões mássicas da miscela de cada bomba, e depois as vazões volumétricas das mesmas, que é a medida que se utiliza nos catálogos de fabricantes de bombas e no cálculo da potência. Esses valores estão na tabela 1 a seguir. 
Tabela 1. Cálculos de vazões volumétricas das bombas

\begin{tabular}{|c|c|c|c|c|c|c|c|c|}
\hline \multicolumn{2}{|c|}{ Bomba } & P8 & P60S2 & P60S1 & P18 & P22 & P120 & P122 \\
\hline Vazão & (ton/h) & 87,8571 & 58,571 & 31,9481 & 24,8484 & 24,6 & 6,07871 & 5,953486 \\
\hline Vazão & $(\mathrm{kg} / \mathrm{s})$ & 24,4048 & 16,27 & 8,87446 & 6,90233 & 6,83333 & 1,68853 & 1,653746 \\
\hline Densidade & $(\mathrm{g} / \mathrm{mL})$ & 0,71938 & 0,7601 & 0,85093 & 0,89029 & 0,90482 & 0,86423 & 0,850498 \\
\hline Densidade & $\left(\mathrm{kg} / \mathrm{m}^{\wedge} 3\right)$ & 719,378 & 760,05 & 850,928 & 890,287 & 904,824 & 864,23 & 850,498 \\
\hline Vazão Q & $\left(\mathrm{m}^{\wedge} 3 / \mathrm{s}\right)$ & 0,03392 & 0,0214 & 0,01043 & 0,00775 & 0,00755 & 0,00195 & 0,001944 \\
\hline
\end{tabular}

Em seguida, foram calculadas as perdas de carga ao longo das tubulações de cada bomba. Para calcular a perda de carga considerando que o tubo fosse reto e de seção constante, a fórmula utilizada, ainda seguindo como referência Moraes (1988), foi a fórmula universal de Darcy, válida para qualquer líquido:

$$
l_{w e}=f \frac{L V^{2}}{D 2 g}
$$

em que $L$ é o comprimento do encanamento em metros, $V$ é a velocidade média do fluido $(\mathrm{m} / \mathrm{s}), D$ o diâmetro da canalização $(\mathrm{m}), \quad g$ a constante da gravidade $\left(\mathrm{m} / \mathrm{s}^{2}\right), f$ o fator de atrito e $l_{w e}$ a perda de carga em metros.

$\mathrm{O}$ fator de atrito $f$ foi encontrado pela fórmula de Churchill, que é válida para qualquer valor de Reynolds e qualquer relação de rugosidade $\mathrm{e}$ diâmetro:

$$
f=8\left[(8 / R e)^{12}+1 /(A+B)^{3 / 2}\right]^{1 / 12}
$$

em que,

$$
\begin{gathered}
A-\left[2,457 \ln \frac{1}{(7 / R \theta)^{0.9}+0,27 e / 0}\right]^{16} \\
B=(37530 / R e)^{16}
\end{gathered}
$$

nas quais, Re é o número de Reynolds, $\varepsilon$ é a rugosidade do tubo e $\mathrm{D}$ é o diâmetro do tubo $(\mathrm{m})$.

O número de Reynolds, já mencionado anteriormente, é um número adimensional que determina o regime de escoamento, laminar ou turbulento, de determinado fluido dentro de um tubo, cujo significado físico é um quociente entre as forças de inércia e as forças de viscosidade:

$$
R e=\frac{D V \rho}{\mu}
$$

em que $\mathrm{D}$ é o diâmetro do tubo, $\mathrm{V}$ é a velocidade média, $\rho$ é a densidade e $\mu$ a viscosidade do fluido.

Por outro lado, para calcular a perda de carga localizada, relacionada aos acidentes da tubulação, como curvas, conexões, alargamentos, reduções e bifurcações, utilizou-se a expressão geral:

$$
l_{w l}=K \frac{V^{2}}{2 g}
$$

em que $\mathrm{V}$ é a velocidade na entrada do acidente $(\mathrm{m} / \mathrm{s}), \mathrm{g}$ é a aceleração da gravidade $\left(\mathrm{m} / \mathrm{s}^{2}\right)$ e K é o coeficiente adimensional de perda de carga de cada acidente. Os valores de $\mathrm{K}$ foram retirados da tabela 2 fornecida por Moraes (1988), que está a seguir. 
Tabela 2. Valores do coeficiente K para acidentes de tubulação

\begin{tabular}{lclc}
\hline \multicolumn{1}{c}{ Peça } & $\mathrm{K}$ & \multicolumn{1}{c}{ Peça } & $\mathrm{K}$ \\
\hline Registro de gaveta aberto & 0,2 & Entrada normal na tubulação & 0,5 \\
Registro de globo aberto & 10 & Saída de canalização & 1 \\
Cotovelo de 90ㅇ & 0,9 & (jato livre ou afogado) & \\
Cotovelo de 45ㅇ & 0,4 & Tê, passagem direta & 0,6 \\
Curva de 90 & 0,4 & Tê, saída de lado & 1,3 \\
Curva de 45 & 0,2 & Tê, saída bilateral & 1,8 \\
\hline
\end{tabular}

Dessa forma, foi necessário fazer medições da viscosidade de cada miscela e dos diâmetros, comprimentos e acidentes de cada parte das tubulações, para que o valor calculado fosse o mais real possível. A viscosidade foi calculada no laboratório com um viscosímetro rotacional, instrumento que mede a viscosidade de cada fluido a partir da dificuldade de manter a rotação de uma ponta de prova numa velocidade constante dentro de uma amostra do fluido. Já os parâmetros relacionados às tubulações foram medidos diretamente com o auxílio de trenas de até cinquenta metros de comprimento, registrando os acidentes existentes e dividindo o caminho de sucção e de recalque de cada bomba em seções de 1 a 6 de acordo com a mudança de diâmetro dos tubos, para possibilitar os cálculos numa planilha do Excel. Assim, após calculadas as perdas de cargas ao longo do equipamento e as perdas de carga localizadas para cada seção, elas foram somadas e, numa somatória de todas as seções de uma bomba, obteve-se a perda de carga total daquela bomba. Isso foi feito para cada uma das bombas que estavam sendo utilizadas, obtendo-se a tabela 3 que está a seguir.

Tabela 3. Perda de carga de cada bomba

\begin{tabular}{|c|c|c|c|c|c|c|c|c|}
\hline \multicolumn{2}{|c|}{ Bombas } & P8 & P60S2 & P60S1 & P18 & P22 & P120 & P122 \\
\hline \multirow{6}{*}{$\begin{array}{l}\text { Perda de } \\
\text { carga ao } \\
\text { longo do } \\
\text { equipa- } \\
\text { mento } \\
\text { Iwe }\end{array}$} & Iwe1 & 0,06406 & 0,24731 & 0,0027 & 0,01816 & 16,83 & 0,6209 & 0,49 \\
\hline & Iwe2 & 1,44149 & 0 & 0,6094 & 13,5803 & 0,3093 & 7,3813 & 3,73 \\
\hline & Iwe3 & 2,26332 & 4,66701 & 3,0604 & 7,32392 & 2,4875 & 3,3247 & 0,62 \\
\hline & Iwe4 & 0 & 0 & 0,4721 & 0 & 4,7372 & 0,0273 & 3,57 \\
\hline & Iwe5 & 0 & 0 & 18,905 & 0 & 0 & 0,001 & 0,01 \\
\hline & Iwe6 & 0 & 0 & 0,3487 & 0 & 0 & 0 & 0,00 \\
\hline \multirow{4}{*}{$\begin{array}{c}\text { Perda de } \\
\text { carga } \\
\text { localizada }\end{array}$} & $|w| 1$ & 0,26216 & 0,61063 & 0,0169 & 0,04661 & 5,5195 & 0,0989 & 0,14 \\
\hline & $|w| 2$ & 1,46317 & 0 & 0,4808 & 2,68473 & 5,2364 & 2,1727 & 1,50 \\
\hline & $|w| 3$ & 2,008 & 5,72729 & 1,706 & 2,53534 & 0,9086 & 1,1088 & 0,83 \\
\hline & $|w| 4$ & 0 & 0 & 0,4888 & 0 & 0,5734 & 0,0036 & 1,62 \\
\hline \multirow[t]{2}{*}{$|w|$} & Iw15 & 0 & 0 & 6,2076 & 0 & 0 & 0 & - \\
\hline & $|w| 6$ & 0 & 0 & 0,4133 & 0 & 0 & 0 & 0,00 \\
\hline Total & lwt & 7,50219 & 11,2522 & 32,712 & 26,189 & 36,602 & 14,739 & 12,51 \\
\hline
\end{tabular}

A partir disso, com os valores obtidos, foi possível calcular os valores da altura manométrica das bombas com a equação (1), anteriormente citada. Ela foi aplicada para cada bomba de um ponto 1 , o primeiro equipamento que fazia parte do caminho de sucção daquela bomba, até um ponto 2 , o último equipamento do caminho de recalque da bomba. E então, com os valores de vazão e altura manométrica, plotaram-se os pontos de operação das bombas em um gráfico com curvas de faixa de operação de bombas $\mathrm{KSB}$, contido num manual de curvas características desse fabricante, para rotação de 1750 RPM e 3500 RPM. Destacou-se nesse gráfico também a faixa de operação das bombas que estavam 
disponíveis na fábrica, para analisar a possibilidade de utilizá-las. Esse gráfico com os pontos plotados está na figura 3 abaixo.

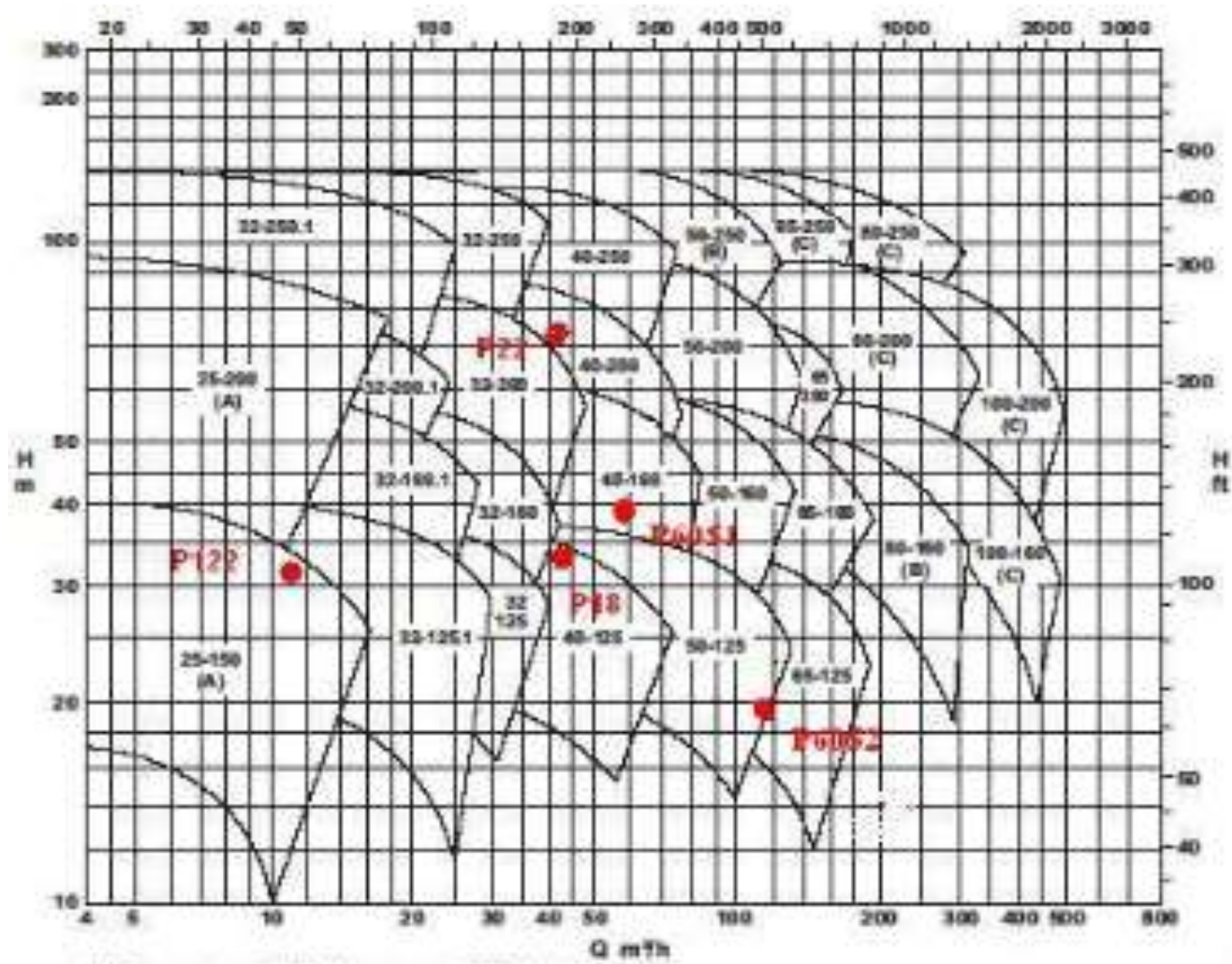

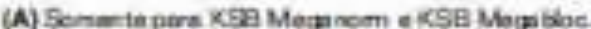

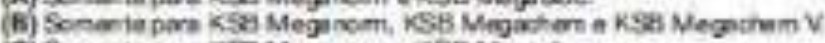

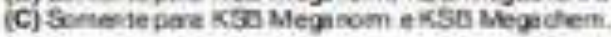
Q u. $\mathrm{gmm}$

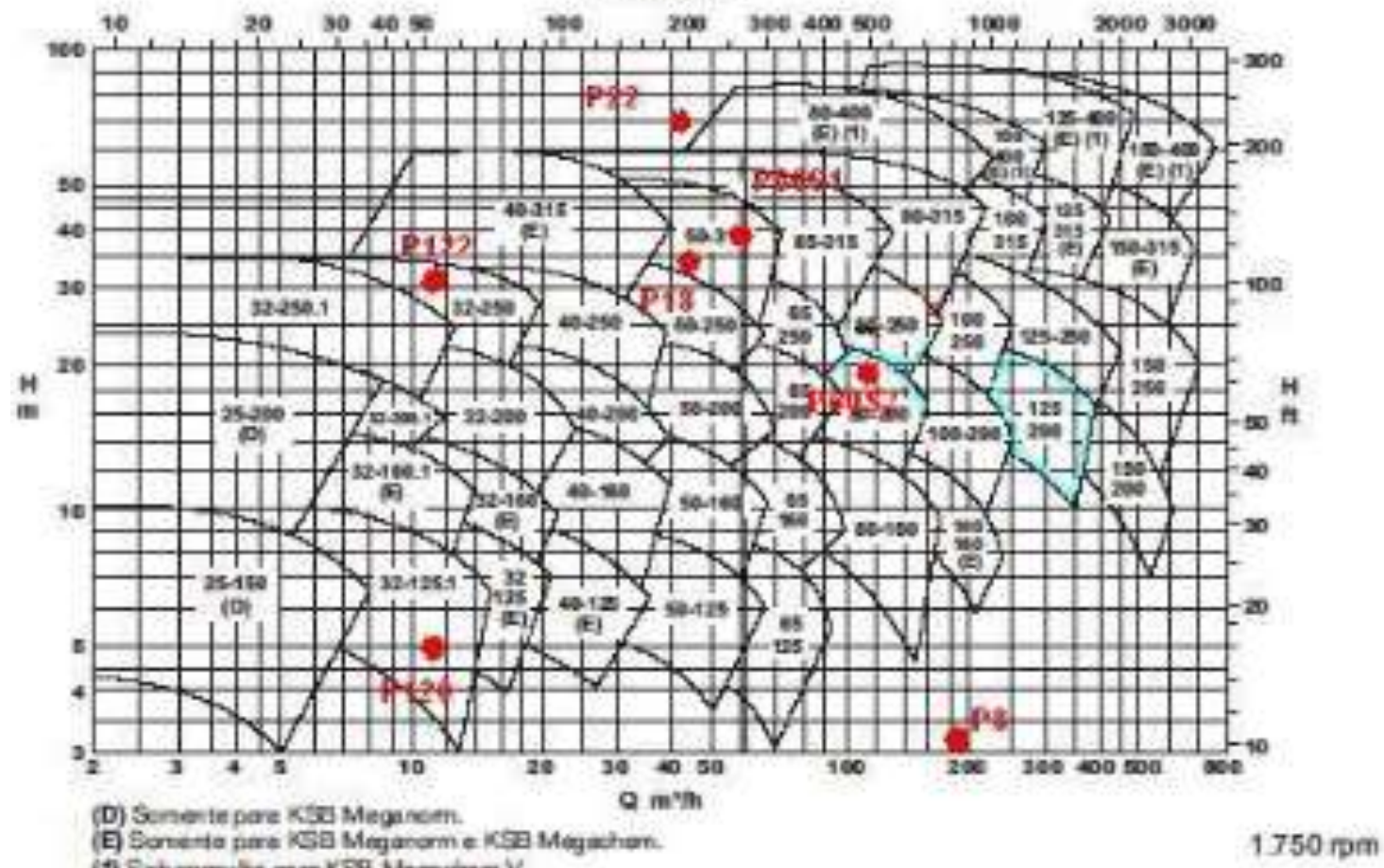

Figura 3. Pontos de operação cada bomba plotados nas curvas de faixas de operação de bombas da KSB 
Com isso, pôde-se analisar quais bombas tinham pontos de operação na faixa indicada para o mesmo tamanho de bomba, ou para um tamanho semelhante, para que se pudesse agrupálas em duplas, escolhendo uma bombareserva que fosse possível de ser utilizada para as duas.

Tendo definido quais bombas seriam agrupadas, a partir da faixa em que caíram os pontos de cada bomba no gráfico e da distância desses pontos às faixas de aplicação das bombas disponíveis na fábrica, definiu-se algumas possibilidades para cada bomba, que incluíam a utilização de uma dessas bombas disponíveis, a compra de uma bomba com rotação de 1750 RPM e a compra de uma bomba com rotação de 3500 RPM. Com as curvas específicas de cada tamanho de bomba, analisou-se qual o diâmetro do rotor que deveria ser usado, a eficiência e a potência necessária dessas bombas para a altura manométrica e a vazão de cada ponto de operação. Exemplos das curvas utilizadas estão a seguir nas figuras 4 e 5 .

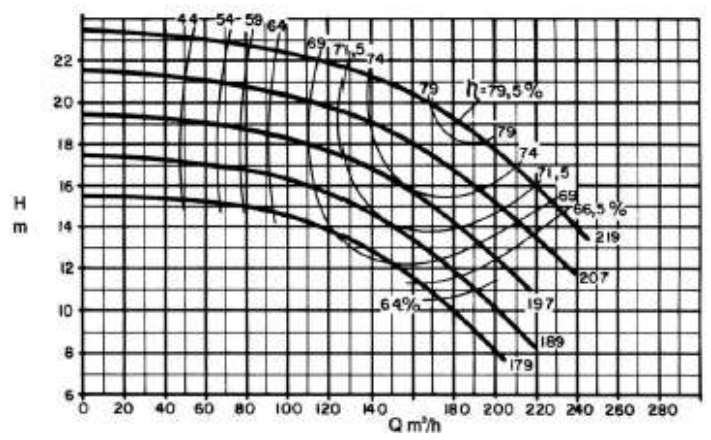

Figura 4. Curva da altura

manométrica pela vazão volumétrica de bomba KSB

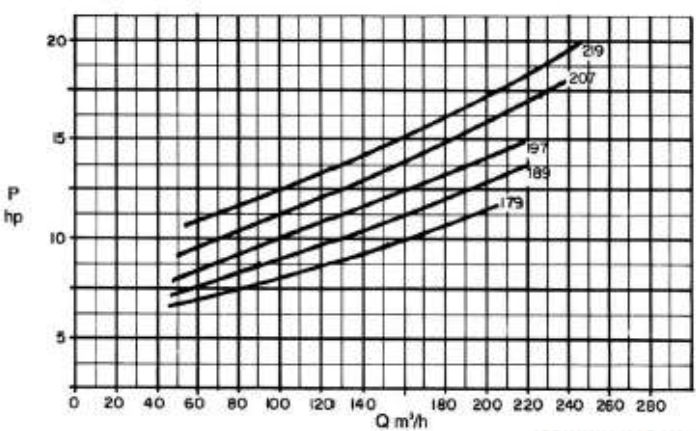

Figura 5. Curva da potência necessária pela vazão volumétrica de bomba KSB

Por fim, com todas essas informações sobre cada conjunto de bombas e suas possibilidades, pôde-se escolher, levando em conta economia e eficiência, qual dessas possibilidades seria a melhor em cada caso.

\section{RESULTADOS}

Tendo seguido o procedimento descrito, definiu-se que para as sete bombas em estudo comprar-se-ia duas bombas para três delas, (sendo que duas estariam agrupadas com uma mesma reserva e a outra com uma reserva só para ela, por estar instalada com um equipamento com vácuo), e utilizar-seia, para as outras quatro, duas bombas disponíveis na fábrica como reservas. $\mathrm{O}$ layout das bombas antes da implantação do projeto de bombas-reserva e depois do projeto está abaixo nas figuras 6 e 7 .

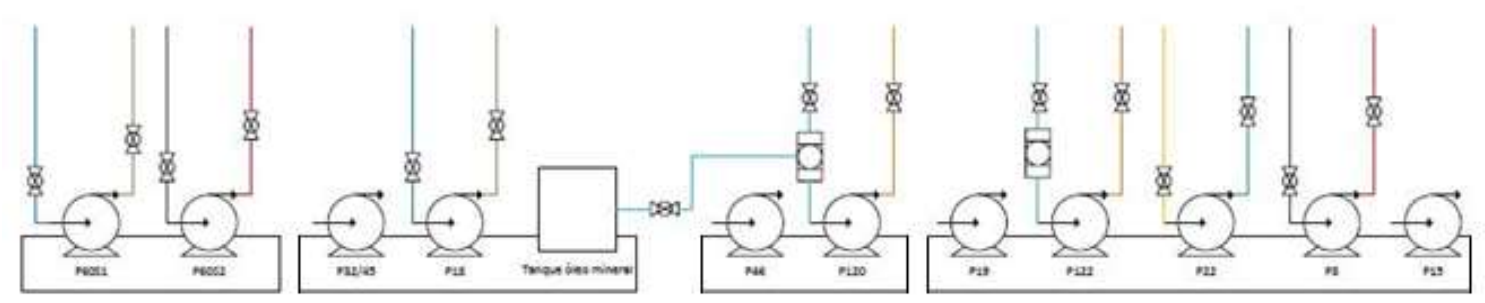

Figura 6. Layout das bombas antes da instalação de bombas-reserva 


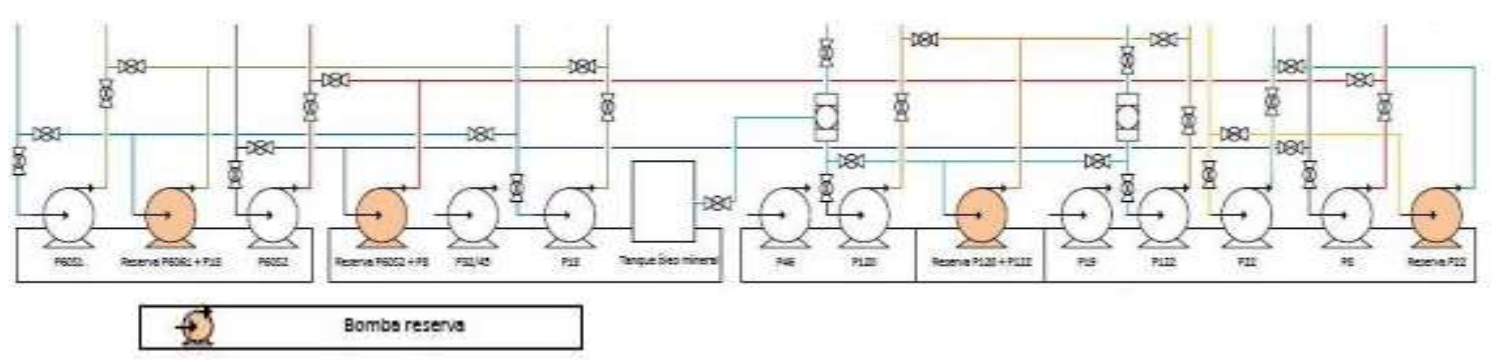

Figura 7. Layout das bombas depois da instalação de bombas-reserva

Com a redução de paradas, e provável fim delas por motivo de manutenção dessas bombas, a fábrica contará com um lucro de $\mathrm{R} \$ 66.688,33$ que ela não receberia se não fosse a eliminação dessas paradas, o que corresponde a um lucro mensal de $\mathrm{R} \$ 6.668,83$.

Dessa forma, para calcular o tempo de retorno da compra das duas bombas, cujo investimento foi de $\mathrm{R} \$ 20.150,00$, foi feito o seguinte cálculo:

$$
\begin{gathered}
t=\frac{20.150,00 \text { reais }}{6.668,83 \text { reuis } / \text { mès }} \\
t=3,021 \text { meses }
\end{gathered}
$$

Além disso, evitando-se a compra de duas bombas pela utilização das bombas já existentes na fábrica, houve uma economia de aproximadamente $\mathrm{R} \$ 20.000,00$ pela boa gestão da informação e, dessa forma, possibilidade de confirmar que essas bombas poderiam ser utilizadas.

\section{CONCLUSÃO}

Portanto, com o trabalho realizado, pôde-se criar um meio de eliminar ou no mínimo reduzir as paradas da fábrica por manutenção das bombas da destilaria e da absorção e dessorção na etapa de extração da fábrica de óleo de soja. As instalações das novas bombas reservas trarão um lucro anual de mais de 66 mil reais que a fábrica estava deixando de receber pelas paradas na produção, sendo que o investimento nas novas bombas será pago em praticamente 3 meses.

Pôde-se concluir também com o projeto, que é muito importante a reutilização de equipamentos dentro de uma fábrica e uma boa gestão da informação na mesma, já que nesse caso elas evitaram a compra de duas bombas, que gerariam gastos de mais de $20 \mathrm{mil}$ reais.

\section{REFERÊNCIAS}

ABIOVE - Associação Brasileira de óleos vegetais. 2012. Disponível em: http://www.abiove.org.br/site/index.php ?page $=$ fotos $\&$ area $=\mathrm{NCO} \mathrm{yLTQ}=\&$ galeri $\mathrm{a}=121$-soja---vagem-e-graos.

[Consultado em 28/06/2013].

BORNIA, A. C. 1995. Mensuração das Perdas dos Processos Produtivos: Uma Abordagem Metodológica de Controle Interno. Programa de Pós-graduação em Engenharia de Produção, Universidade Federal de Santa Catarina, Florianópolis.

CORRÊA, T. E. 2010. Simulação e melhorias de uma unidade de extração de aromáticos. UFRGS.

CUNHA, R. B; CASTRO, M. S; FONTES, W. 2006. Espectrometria de massa de proteínas. Revista Biotecnologia, Ciência \& Desenvolvimento. Ano IX, n⿳30, Janeiro/Junho. 
EMBRAPA. 2001. Tecnologia para produção do óleo de soja: descrição das etapas, equipamentos, produtos e subprodutos. Londrina, Paraná.

KSB. Manual de curvas características KSB. 2009. $\mathrm{N}^{\circ}$ A2740/42/44.1P/E/S/6, 29/01/2009.

MORAES, D. J. 1988. Transporte de líquidos e gases. São Carlos, UFSCar.

PARAÍSO, P. R. 2001. Modelagem e análise do processo de obtenção do óleo de soja. UNICAMP.

PETROBRÁS DISTRIBUIDORA. Ficha de Informação de Segurança de Produto Químico - FISPQ. 2011. BR 608, 17/02/2011.

ROITMAN, V. 2002. Curso de operadores de refinaria da Petrobrás Operações unitárias. Curitiba, Paraná.

SILVA, M. 2003. Manual de

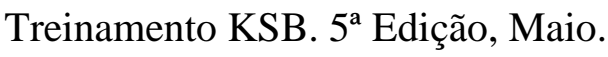

